\title{
Strengthening primary care: \\ addressing the disparity between vertical and horizontal investment
}

Recently we have seen an unprecedented increase of financial support to improve health care in developing countries estimated at 26\% between 1997 and 2002 , from $\$ 6.4$ billion to $\$ 8.1$ billion. ${ }^{1}$ While the magnitude of such an investment is a positive development, the vast majority of aid has been allocated towards disease-specific projects (termed 'vertical programming') rather than towards more broad-based improvements in population health, such as preventive measures, primary care services, and health workforce development (termed 'horizontal programming').

For instance, the initiatives of the Bill and Melinda Gates and Clinton Foundations usually focus on specific communicable diseases: $60 \%$ address 'big diseases' (HIV/AIDS, malaria, and tuberculosis). Rwanda, for example, with an HIV prevalence rate of $3.1 \%^{2}$ and an annual health budget of $\$ 37$ million, ${ }^{3}$ received $\$ 187$ million since 2003 exclusively for HIV/AIDS.

\section{ALMA ATA, HORIZONTAL AND VERTICAL PROGRAMMES}

Thirty years ago, in 1978, the Alma-Ata Declaration pointed to the importance of community-oriented comprehensive primary health care for all nations. Improving health required changes in economic, social, and political structures, in addition to access to health care. In this comprehensive or 'horizontal' healthcare concept, health care is also a basic human right that requires community participation.

Some have argued that the Alma-Ata concepts were unattainable because of the costs and numbers of trained personnel required. From this perspective, a selective disease-oriented approach could address the greatest disease burden in the community in less developed countries. ${ }^{4}$

The two positions differ both philosophically and practically. The selective method is based on a short-term outlook that solves a given health problem (HIV/AIDS) through the application of specific measures. Comprehensive primary health care is carried out through a longterm process that seeks to tackle the overall health problems through the creation of an accessible permanent institutional infrastructure for 'general health services'.

The AIDS epidemic of the late 1970s and early 1980s generated a strong impetus to develop vertical programmes. This selective strategy has been supported by the World Bank, UNICEF, and Centres for Disease Control and Prevention. ${ }^{5}$

\section{EFFECTIVENESS OF VERTICAL PROGRAMMES}

An overview of the literature revealed that, despite the large sums invested, vertical programmes (on HIV/AIDS, malaria, and tuberculosis) performed poorly. ${ }^{6}$ For example, despite a tenfold increase in external financing for tuberculosis control in low-income countries over the last decade, only $27 \%$ of active pulmonary tuberculosis patients have access to the direct observation of treatment strategy. ${ }^{7}$ By mid 2004 , less than $5 \%$ of AIDS patients in subSaharan Africa were receiving treatment compared to over $50 \%$ in the Americas. ${ }^{8}$

This marks the failure of vertical programming to meet its main objective: a better coverage of those with the highest needs. While acute respiratory infections represent $26 \%$ of the total burden of communicable diseases in the developing world, less than $2.5 \%$ of direct funding is allocated to them. AIDS, constituting 31\% of the burden, receives $46 \%$ of all direct donor funds. ${ }^{9}$ Vertical disease-oriented programmes, in their single-minded focus, largely ignore patients' needs for access to broader healthcare services. ${ }^{10}$

In addition, vertical programmes create duplication, whereby each disease control

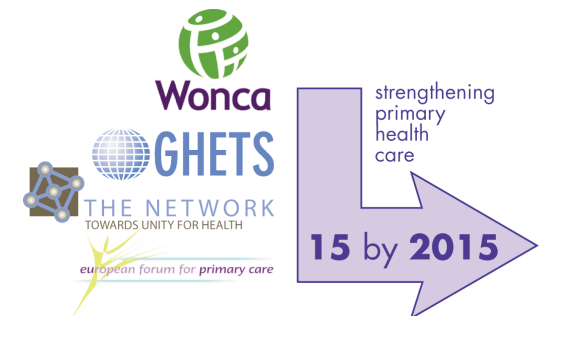

programme requires its own bureaucracy, leads to inefficient facility utilisation by recipients, and may lead to gaps in care especially in patients with multiple comorbidities. Moreover, vertical programmes that are funded externally undermine government capacity by reducing the responsibility of the state to improve health care through its own services.

Well-financed vertical programmes funded by international donors have 'diverted' skilled local health personnel away from the local (primary) healthcare system. In Ethiopia, for example, to implement the Global Fund proposal, local medical staff were hired on consultancy contracts at triple the public sector salaries. As a result, the health sector became vertically organised, with staff moving from one section to the next, jeopardising access to overall health services and raising deep concerns regarding equity. ${ }^{11}$ This type of internal 'brain drain' has devastating consequences and undermines critical primary healthcare services.

\section{EFFECTIVENESS OF HORIZONTAL PROGRAMMES}

Horizontal programming has been addressed in studies of 'effectiveness of primary care'. The stronger a country's primary healthcare system, the higher the system's quality and cost-effectiveness and the greater its impact on health. ${ }^{12}$ Where income disparities are widest (most developing countries), the positive impact of primary care in redressing health disparities is greatest. ${ }^{13}$

The World Health Report 2006 states that adequate treatment of chronic diseases requires a shift towards community-based and patient-centred paradigms of care, ${ }^{14}$ which are components of the horizontal approach. Community-based primary health care is, with family medicine and primary care nursing as the clinical 
disciplines, a cost-effective way to contribute to this shift. An analysis of preventable deaths in children concluded that in the 42 countries accounting for $90 \%$ of child deaths worldwide, $63 \%$ could have been prevented by full implementation of primary care where the common problems of diarrhoea, pneumonia, measles, malaria, HIV/AIDS, preterm delivery, neonatal tetanus, and neonatal sepsis could be addressed in one, integrated clinical setting. ${ }^{15}$

\section{TOWARDS SUSTAINABLE HEALTH CARE}

Currently, under-funded primary healthcare providers and clinics in developing countries have scarce resources to build systems that respond to the needs of patients and communities. There is a need for integration of vertical programmes into local health facilities to achieve sustainable disease control. ${ }^{16}$

Integrating curative and preventive care in particular has merits, such as the potential to detect a patient with tuberculosis among those coughing, or offering vaccination to patients with whom the primary care practitioner has established a relationship. Integration overcomes vertical programmes' narrow focus on only a fraction of the care needed. A 'code of best practice for disease control programmes to avoid damaging healthcare services in developing

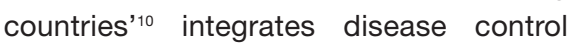
activities in health centres, which offer patient-centred care.

\section{RECOMMENDATION: '15 BY 2015'}

There is a need for a new global strategy to achieve a synergy among person- and community-focused and disease-focused approaches. To achieve this, the World Organisation of Family Doctors (Wonca) in collaboration with Global Health through Education, Training and Service (GHETS), with The Network: Towards Unity for Health, (The Network: TUFH), and the European Forum for Primary Care (EFPC), call upon the new International Health Partnership and upon funding organisations, such as the Global Fund, the World Bank, the Bill and Melinda Gates Foundation, and the World Health Organization, to assign primary health care a pivotal role in the provision of their activities and to support its development in a systematic way.

To launch the debate, we propose that by $2015,15 \%$ of the budgets of vertical disease-oriented programmes be invested in strengthening well-coordinated, integrated local primary healthcare systems and that this percentage would increase over time. Such an investment would improve developing nations' capacity to address the majority of health problems through a generic, well-structured, comprehensive primary care system. The time is right and movement in this direction is beginning to take place.

Now that there are unprecedented investments in world health, an increased investment in horizontal care will enable local communities, districts, provinces, and countries to build sustainable, costeffective primary healthcare systems which will accelerate the achievement of equity and improved health. We believe that the ' 15 by 2015 ' campaign could act as a vehicle to reach this goal.

\section{Jan De Maeseneer}

Head of Department of Family Medicine and Primary Health Care, Ghent University, Belgium. Chairman European Forum for Primary Care and Secretary General of The Network: Towards Unity for Health.

\section{Chris van Weel}

Professor and Chairman Department of Family Medicine, Radboud University Medical Center, Nijmegen, The Netherlands. President of the World Organisation of Family Doctors, Wonca.

\section{David Egilman}

Clinical Associate Professor, Brown University, Providence RI, US. Founder and Board President of GHETS (Global Health through Education, Training and Service).

\section{Khaya Mfenyana}

Head of Department of Family Medicine, Walter Sisulu University, Mthatha, South-Africa, President of Wonca-Africa.

\section{Arthur Kaufman}

Vice President for Community Health, University of New Mexico Health Sciences Center, US.

\section{Nelson Sewankambo}

Dean Faculty of Medicine, Makerere University, Kampala, Uganda.

\section{Acknowledgements}

We thank Mieke van Driel for her assistance in editing the manuscript.

REFERENCES
1. Anonymous. Engaging for health. Eleventh General Programme of Work 2006-2015. Geneva: World Health Organization, 2006.

2. UNAIDS. Rwanda. Available at: http://www.unaids.org/en/Regions_Countries/Countri es/rwanda.asp (accessed 6 Dec 2007)

3. Ministry of Health, Republic of Rwanda. Rwanda national health accounts 2003. Kigali: Ministry of Health, 2006.

4. Walsh JA, Warren KS. Selective primary health care: an interim strategy for disease control in developing countries. Soc Sci Med 1980; 14: 145-163.

5. Unger JP, Killingsworth JR. Selective primary health care: a critical review of methods and results. Soc Sci Med 1986; 22: 1001-1013.

6. De Maeseneer J, Willems S, De Sutter A, et al. Primary health care as a strategy for achieving equitable care: literature review commissioned by the Health System Knowledge Network of CSDH. http://www.wits.ac.za/chp/hskn.htm (accessed 6 Dec 2007).

7. Lambert ML, Van der Stuyft P. Global Health Fund or Global Fund to fight AIDS, Tuberculosis and Malaria? [editorial]. Trop Med Int Health 2002; 7(7): 557-558.

8. Anonymous. Coverage and need for antiretroviral treatment. Geneva: World Health Organization, 2004.

9. Shiffman J. Donor funding priorities for communicable disease control in the developing world. Health Policy Plan 2006; 21: 411-420.

10. Unger JP, De Paepe P, Green A. A code of best practice for disease control programmes to avoid damaging health care services in developing countries. Int $J$ Health Plann Manage 2003; 18: S27-S39.

11. Banteyerga H, Kideno A, Bennet S, Stillman K. System-wide effects of the Global Fund in Ethiopia: baseline study report. Partners for Health Reform plus (PHR plus). Bethesda, MD: USAID, 2005.

12. Starfield B, Shi L, Macinko J. Contribution of primary care to health systems and health. Milbank Q 2005; 83: 457-502.

13. Shi L, Starfield B, Politzer R, Regan J. Primary care, self-rated health, and reductions in social disparities in health. Health Serv Res 2002; 37(3): 529-550.

14. Anonymous. The World Health Report 2006. Working together for health. Geneva: World Health Organization, 2006: p19.

15. Jones G, Steketee RW, Black RE, et al. How many child deaths can we prevent this year? Lancet 2003 362: 65-71.

16. Wilkinson D. Tuberculosis and health sector reform: experiences of integrating tuberculosis services into the district health system in rural South Africa. Int $J$ Tuberc Lung Dis 1999; 3: 938-943.

\section{FURTHER READING}

Wonca: http://www.globalfamilydoctor.com GHETS: http://www.ghets.org/ The Network TUFH: http://www.the-networktufh.org EFPC: http://www.euprimarycare.org

DOI: 10.3399/bjgp08X263721

\section{ADDRESS FOR CORRESPONDENCE}

\section{Jan De Maeseneer}

Department of Family Medicine and Primary Health Care, Ghent University, De Pintelaan 185, UZ 1K3, B-9000 Ghent, Belgium.

E-mail: jan.demaeseneer@ugent.be 